\title{
Cross-sectional study on the adherence to malaria guidelines in lakeshore facilities of Buyende and Kaliro districts, Uganda
}

Henry Kaula ${ }^{1,2}$, Sylvia Kiconco ${ }^{1}$ and Luigi Nuñez $2^{*}$ iD

\begin{abstract}
Background: Uganda adopted the Integrated Management of Malaria (IMM) guidelines, which require testing all suspected cases of malaria prior to treatment and which have been implemented throughout the country. However, adherence to IMM guidelines has not been explicitly investigated, especially in lakeshore areas such as Buyende and Kaliro, two districts that remain highly burdened by malaria. This study assesses the level of adherence to IMM guidelines and pinpoints factors that influence IMM adherence by health providers in Buyende and Kaliro. A crosssectional study among 197 patients and 26 healthcare providers was conducted. The algorithm for adherence to IMM guidelines was constructed to include physical examination, medical history, laboratory diagnosis, and anti-malarial drug prescription. Adherence was measured as a binary variable, and binary regression was used to identify factors associated with adherence to IMM guidelines.

Results: Only 16 (8.1\%) of the 197 patients had their medical history and physical examinations taken, while the majority (65.5\%) of the patients were recommended for malaria (laboratory) testing. Regarding adherence to prescription guidelines, 127 (64.5\%) of the patients received artemisinin combination therapy (ACT) drug prescription. On the other hand, $18.6 \%$ of those who tested negative received an ACT drug/prescription and 10.1\% tested positive but did not receive an ACT drug or prescription. Overall adherence to IMM guidelines was only 3.1\%. The only factor that significantly influenced adherence to IMM guidelines was training; healthcare providers who had attended recent training on these guidelines were almost three times more likely to adhere to the IMM guidelines compared to those who had not attended recent training (OR=2.858, 95\% Cl 1.754-4.659).

Conclusions: The findings indicate very low levels of adherence to IMM guidelines among healthcare workers in the lakeshore areas of Kaliro and Buyende districts. Since adherence was independently influenced, majorly by training healthcare workers on these guidelines, recommendations include facilitating training on IMM guidelines throughout Uganda.
\end{abstract}

Keywords: Uganda, Malaria, Integrated Management of Malaria, Adherence, Kaliro, Buyende, Training

\section{Background}

Although sub-Saharan Africa continues to bear the largest burden of malaria with $88 \%$ of all cases and 9 in every 10 deaths globally, recent studies show that malaria is on the decline in the African region; there was a decline of $48 \%$ in the number of cases and $66 \%$ in deaths between

*Correspondence: nunezluigi@icloud.com

2 PACE Uganda, PSI, Kampala, Uganda

Full list of author information is available at the end of the article
2000 and 2015 [1]. These declines may be attributed to improved access to malaria prevention and control tools, such as insecticide-treated bed nets (ITNs), indoor residual spraying (IRS), and artemisinin-based combination therapy (ACT). To consolidate the achievements in malaria prevention and control, the World Health Organization (WHO) updated its framework concerning malaria by requiring all countries where malaria is endemic to ensure that all suspected cases of the disease are tested via microscopy or rapid diagnostic test (RDT) 
and that every confirmed case is treated with a qualityassured anti-malarial drug [2].

Following the update of the WHO Framework for malaria prevention and control in 2012, Uganda, similarly to other countries where malaria is endemic, adopted these updated policies [3]. Uganda updated its national malaria treatment guidelines that same year to indicate first-line treatment and their alternatives for all cases of malaria, which includes any artemisinin-based combinations that has been recommended by the WHO and Ministry of Health $(\mathrm{MOH})$ and is registered with the National Drug Authority. Adherence to the treatment guidelines has numerous benefits including improved use of antimalarial drugs and reductions in the current high costs of ACT. It is, therefore, important that healthcare providers in both public and private sectors adhere to these guidelines for effective control of the disease.

Despite these efforts, Uganda has the third highest number of deaths from malaria and some of the highest recorded rates of malaria transmission in Africa, especially in areas around Lake Kyoga [4]. Both Buyende and Kaliro, two districts bordering Lake Kyoga, have hyperendemic transmission intensity rates $(\geq 75 \%)$ for malaria at 85 and $100 \%$ of their populations, respectively. Meanwhile, these two districts are among those districts specifically targeted with heavy malaria interventions for being hyperendemic areas [5]. Despite many interventions, such as distributing free ITNs and increasing access to malaria diagnostic services and ACT by the Government of Uganda in the two districts, the area remains highly malaria burdened [5].

Several factors, including adherence to Integrated Management of Malaria (IMM) guidelines, may be majorly contributing to this consistent burden. Poor adherence, for example, can lead to increased malaria burden, parasite resistance, resource wastage, and treatment failure. This research sought to determine the level of adherence and associated factors to IMM guidelines among healthcare providers in Buyende and Kaliro. Findings may assist development partners and policy makers in identifying gaps related to IMM adherence and avert possible consequences, such as drug resistance, loss of lives and increased medical costs.

\section{Methods}

\section{Study area}

This study was conducted in the lakeshores of the Buyende and Kaliro districts in Uganda; lakeshores were defined as parishes that share borders with Lake Kyoga in Buyende and Kaliro districts [6]. Both Buyende and Kaliro are in Busoga, a sub-region in Eastern Uganda and surrounded by Lake Kyoga. Buyende, difficult to reach due to poor transport infrastructure, has a total population of 323,100 [7]. Kaliro has a total population of 236,200 [7]. Global positioning system (GPS) coordinates of the study facilities were taken, and Global Information System (GIS) software was used to generate a map of these areas.

\section{Study design}

This study followed a cross-sectional design where data were collected from selected health facilities in September and October 2016 using a structured questionnaire. Primary data including socio-demographics, illness diagnoses, and medicine prescriptions were collected from patients and/or their attendants exiting the selected health facilities. Where available, the researcher or research assistant looked at patients' medical forms to triangulate the information collected through the interview. Additionally, data on attitudes was collected from healthcare providers who were directly involved in malaria management in the selected health facilities.

\section{Study exposure and outcome}

Exposure variables in this study were healthcare provider factors, such as cadre of healthcare providers, age, gender, level of education, training on national malaria guidelines, and health facility-related factors, including the type of facility and ownership. These factors were examined to see if they influence adherence to IMM guidelines. The individual health worker was linked to all the patients he/she had treated in order to establish whether the health worker had adhered to the guidelines. The study outcome was level of adherence to IMM guidelines. Adherence was defined as the proportion of diagnosis and prescriptions made in line with the national malaria management guidelines.

\section{Sample size and participant selection}

Using the Leslie Kish 1965 formula [8],

$$
\mathrm{n}=\left(\mathrm{Z}_{0.95}\right)^{2}\left(\mathrm{P}(1-\mathrm{P}) / \mathrm{D}^{2}\right)
$$

with $95 \%$ confidence interval (i.e. $Z_{0.95}=1.96$ ), $31 \%$ proportion (P) for fever in Uganda [9], and absolute precision (D) of 5\%, a total sample of 329 participants was considered sufficient for this study. Buyende district has a total of 23 health facilities (5 at the lake shores) and while Kaliro has 21 (6 at the lakeshores) [6]. This study included all health facilities (11) along the shores of Lake Kyoga, 5 of which were in Buyende and 6 in Kaliro. These were the only ones that had information regarding the number of patients with fevers treated at each facility prior. Exit interviews were used, and every patient participant who met the inclusion criteria was included. 
Health workers involved in the diagnosis and treatment of suspected malaria were also included in the study. Private health facilities were anticipated to have a client flow of 10-20 clients a day while public health facilities had at least 50 clients. A total of 286 patients were screened; 223 were eligible, i.e., seeking treatment for illness including fever. Of the 223 eligible caregivers, 11\% (26) declined to participate in the study. Extending the enrollment for this study was not possible due to insufficient funding.

\section{Data collection}

Data were collected electronically using the Open Data Kit (ODK) software installed on Samsung Galaxy smart phones. Each phone was enabled to capture GPS coordinates to provide facility locations. The client/patient caregiver questionnaires were programmed and uploaded using ODK. The programmed tool had built-in validation steps to ensure no errors were made. Adult patients and caregivers of children below the age of 15 years were interviewed on exit from selected facilities after seeking diagnosis and treatment of fever. The data collectors were positioned at the exit of the outpatient side of the health facility to interview the patient participants while following interview protocol procedures to obtain the required information. Information regarding laboratory diagnosis and prescription was verified from a patient's medical form or book while clinical diagnosis information was as reported by the participant. Similarly, questionnaires were administered to health workers who directly managed patients with suspected malaria.

\section{Data management and analysis}

The data collected were downloaded as a Microsoft Excel workbook and then exported to SPSS version 17 for analysis. For univariate analysis, each individual variable was summarized using frequency tables, charts and graphs. For bivariate analysis, each independent variable was cross-tabulated with the dependent variable (adherence to national malaria management guidelines) to establish possible associations. The Chi Square test, or Fisher Exact Test (FET) for cases when the expected number was less than 5 , was used to determine association between these categorical variables at a statistical significance level of 0.05 . For multivariate level analysis, binary regression was conducted on those highly significant independent variables to determine independent factors' influence on adherence to the national malaria guidelines, with 95\% confidence intervals for the odds ratios and significance levels of 0.05 . Data quality was ensured through comprehensive training of research assistants, pre-testing of tools, and constant supervision.

\section{Results}

Baseline characteristics of the study population

From Table 1, a total of 286 patients were screened at the facility exit after receiving treatment. Nearly half (47.9\%) of the patients screened were from Buyende, and the rest (52.1\%) were from Kaliro; $67.5 \%$ of the screened patients were female; $78.0 \%$ sought treatment for an illness that included fever, and $57.0 \%$ of this sub-set sought treatment for themselves. Nearly all (96.4\%) of the screened patients were seeking treatment for a current episode of fever for the first time at the surveyed health facilities. The total number of patients or caregivers who consented to participate in the study was 197 (88.3\%). Every patient who consented was seeking treatment for an illness that included fever, and only this sub-group was considered for further analysis, as is presented in the Tables. Patients' average age was $19.6( \pm 18.1)$ years.

\section{Level of adherence to malaria diagnosis guidelines}

Table 2 shows level of adherence to malaria diagnosis guidelines, as reported by patients. Most health providers enquired about the patient's age (97.0\%), symptoms of the illness and when it began (94.9\%), and history of fever $(80.2 \%)$. However, only $95(48.2 \%)$ of the patients were

Table 1 Baseline information of the study participants $(\mathrm{n}=\mathbf{2 8 6})$

\begin{tabular}{lcc}
\hline Variable & Frequency & Per cent \\
\hline Number of patients per district & 137 & \\
Buyende & 149 & 57.9 \\
Kaliro & 286 & 100.0 \\
Total & & \\
Distribution of gender & 193 & 67.5 \\
Female & 93 & 32.5 \\
Male & 286 & 100.0 \\
Total & 50 & \\
Sought treatment for an illness that included fever & 17.5 \\
No & 223 & 78.0 \\
Yes & 13 & 4.5 \\
Did not respond to the question & 286 & 100.0 \\
Total & & \\
For whom care/treatment was sought & 127 & 57.0 \\
Self & 94 & 42.1 \\
Child & 2 & 0.9 \\
Both self and child & 223 & 100.0 \\
Total & & \\
Distribution of age & 82 & 41.6 \\
5 years old and below & 115 & 58.4 \\
Above 5 years old & 197 & 100.0 \\
Total & & \\
\hline
\end{tabular}

Source: primary data 
Table 2 Level of adherence to malaria diagnosis guidelines as reported by patients

\begin{tabular}{lcr}
\hline Variable & Frequency & Per cent \\
\hline Healthcare provider asked about symptoms of the illness & \\
No & 10 & 5.1 \\
Yes & 187 & 94.9 \\
Total & 197 & 100.0 \\
Healthcare provider asked if the patient has fever/history of fever & \\
No & 39 & 19.8 \\
Yes & 158 & 80.2 \\
Total & 197 & 100.0 \\
Healthcare provider asked about any signs of severe illness (headache, \\
convulsions, unable to eat or drink, vomiting) \\
No & 102 & \\
Yes & 95 & 51.8 \\
Total & 197 & 48.2 \\
Healthcare provider asked for patient's age & 100.0 \\
No & 6 & \\
Yes & 191 & 3.0 \\
Total & 197 & 97.0 \\
Healthcare provider weighed patient using a weighing scale & 100.0 \\
No & 140 & \\
Yes & 57 & 71.1 \\
Total & 197 & 28.9 \\
Healthcare provider took body temperature with a thermometer & 100.0 \\
No & 153 & \\
Yes & 44 & 22.3 \\
Total & 197 & 100.0
\end{tabular}

Healthcare provider took both medical history and physical examinations appropriately

$\begin{array}{lrr}\text { No } & 181 & 91.9 \\ \text { Yes } & 16 & 8.1 \\ \text { Total } & 197 & 100.0\end{array}$

Provider recommended/offered a blood test (RDT and microscopy) for malaria (even if patient refused test)

$\begin{array}{lrr}\text { No } & 68 & 34.5 \\ \text { Yes } & 129 & 65.5 \\ \text { Total } & 197 & 100.0\end{array}$

Patient, among those offered a test, actually took the test $(n=129)$ $\begin{array}{lrr}\text { Yes } & 129 & 100.0 \\ \text { No } & 0 & 0.0\end{array}$

$\begin{array}{lll}\text { Total } & 129 & 000.0\end{array}$

Type of test done $(n=129)$
RDT
RDT

$\begin{array}{lrr}\text { RDT } & & 96 . \\ \text { Microscopy } & 5 & 3.9\end{array}$

$\begin{array}{lll}\text { Total } & 129 & 100.0\end{array}$

Proportion of providers who fully adhered to malaria diagnosis guidelines ${ }^{\mathrm{a}}$

$\begin{array}{lrr}\text { No } & 185 & 93.9 \\ \text { Yes } & 12 & 6.1 \\ \text { Total } & 197 & 100.0\end{array}$

Source: primary data

a Full adherence refers to patients whose providers adhered to all medical history taking questions, physical examinations questions and malaria laboratory testing reportedly asked about signs of severe illness, including headaches, convulsions, and vomiting. Regarding physical examinations, only 28.9 and $22.3 \%$ of the 197 patients had their body weight and temperature taken using a weighing scale and a thermometer, respectively. The number of patients who reported that their health providers conducted both medical history and physical examinations was only 16 (8.1\%).

In terms of laboratory diagnosis, 129 (65.5\%) of the patients were recommended for malaria testing and all $(100.0 \%)$ of them went ahead to have the test done. Among the patients who actually took the test, RDT was the most common type of malaria testing done (96.1\%) and only $3.9 \%$ had a microscopy test. Additionally, only about half (52.4\%) of the 124 patients who had RDT done had a positive test result and $80.0 \%$ of those who took microscopy had a positive blood smear test for malaria.

The findings indicate that the overall level of adherence to malaria diagnosis (medical history, physical examination, and laboratory testing) was only $6.1 \%$ of the 197 patients.

\section{Level of adherence to malaria drug (ACT) prescriptions guidelines}

In total, 127 (64.5\%) of the 197 patients who participated in this study received ACT drugs or ACT drug prescription as shown in Table 3.63.0\% of patients who received ACT drugs or prescription had received it after a malaria test. The results show that $24(18.6 \%)$ of the patients who had negative malaria test were still given ACT drug prescriptions, while $13(10.1 \%)$ who had positive test results were not given $\mathrm{ACT}$ prescriptions by the providers.

Overall, the level of adherence to the national malaria management guidelines (clinical, laboratory diagnosis, prescription) among the patients was very low at only $3.1 \%$ of the patients being managed in accordance with IMM guidelines.

\section{Provider-related factors and adherence to national malaria management guidelines}

Patients reported 26 different providers among the 11 health facilities. As shown in Table 4, there were significant differences between the levels of adherence for providers who had training on national malaria treatment guidelines in the past 3 years and those who did not have the training $\left(\mathrm{X}^{2}=7.564, \mathrm{p}=0.014\right)$ as well as among the professional cadres $\left(\mathrm{X}^{2}=27.468, \mathrm{p}<0.001\right)$. There was no significant difference in the level of adherence to the guidelines as far as the other provider-related factors were concerned. Furthermore, there was no significant difference in the level of adherence between those who expressed positive perceptions and those with negative 
perceptions about the key components of IMM guidelines $(\mathrm{p}>0.05)$.

\section{Facility-related factors and adherence to national malaria management guidelines}

The results in Table 5 show that none of the providers from public health facilities had their patients report adherence to the national treatment guidelines for malaria while $75 \%$ of all the providers whose patients reported adherence were in private not-for-profit facilities. There was a statistically significant association between facility ownership and the level of adherence to malaria treatment guidelines $\left(\mathrm{X}^{2}=13.517, \mathrm{p}=0.001\right)$.

Table 5 also shows that the level of facility was not a statistically significant factor in reported adherence to IMM guidelines. Level II facilities are the "lowest level of formal healthcare delivery" and are "mostly staffed by nurse aides and qualified nurses," whereas Level III facilities are mid-level primary care facilities that provide for "basic laboratory services, maternity care and

Table 3 Level of adherence to malarial drug (ACT) prescriptions guidelines, reported by patients

\begin{tabular}{|c|c|c|}
\hline Variable & Frequency & Per cent \\
\hline \multicolumn{3}{|c|}{ Patient received $\mathrm{ACT}$ drug or $\mathrm{ACT}$ drug prescription } \\
\hline No & 70 & 35.5 \\
\hline Yes & 127 & 64.5 \\
\hline Total & 197 & 100.0 \\
\hline \multicolumn{3}{|c|}{$\begin{array}{l}\text { Patient, among those who received ACT drug/prescription, received } \\
\text { ACT drug/prescription after a malaria test }(n=127)\end{array}$} \\
\hline No & 47 & 37.0 \\
\hline Yes & 80 & 63.0 \\
\hline Total & 127 & 100.0 \\
\hline \multicolumn{3}{|c|}{ Test (RDT and microscopy) results and $\mathrm{ACT}$ drug prescriptions } \\
\hline Negative (did not receive ACT prescription) & 36 & 27.9 \\
\hline Negative (received ACT drug prescription) & 24 & 18.6 \\
\hline $\begin{array}{l}\text { Positive (did not receive ACT drug prescrip- } \\
\text { tion) }\end{array}$ & 13 & 10.1 \\
\hline Positive (received ACT drug prescription) & 56 & 43.4 \\
\hline Total & 129 & 100.0 \\
\hline \multicolumn{3}{|c|}{$\begin{array}{l}\text { Overall proportion of patients whose providers adhered to national } \\
\text { IMM guidelines (among all } n=197)^{\mathrm{a}}\end{array}$} \\
\hline No & 191 & 97.0 \\
\hline Yes & 6 & 3.1 \\
\hline Total & 197 & 100.0 \\
\hline
\end{tabular}

Source: primary data

a Overall proportion of adherence to national malaria management was computed and means that the providers adhered to both malaria diagnosis and prescriptions guidelines. Prescription adherence meant that a provider prescribed anti-malarial after testing for malaria and only to those who tested positive. Prescriptions of ACT to patients without testing for malaria and to those with negative test results constituted non-adherence to prescription and were factored in computing for overall level of adherence to guidelines inpatient care (often for onward referral)" and are "usually staffed by nurse aides, qualified nurses and clinical officers (physician assistants)" [10]. These types of health facilities focus on preventing and treating infectious illnesses.

\section{Multivariate analysis of factors associated with adherence to national malaria management guidelines}

Multivariate analysis was conducted for highly significant variables (professional cadre, whether the provider receiving training on IMM guidelines in the past 3 years, ownership of facility). From Table 6, only training in the last 3 years $(O R=2.858,95 \%$ CI $1.754-4.659, \mathrm{p}<0.001)$ was independently associated with adherence to the national malaria management guidelines at the multivariate level. Health workers who received training on the national malaria management guidelines in the past 3 years were about three times more likely to adhere to the guidelines compared to those who did not. There was no significant difference in the levels of adherence to the guidelines by professional qualification and ownership of the facility $(\mathrm{p}>0.05)$.

\section{Discussion}

This is one of the first studies to have assessed the level of adherence to national malaria management guidelines by healthcare workers in Kaliro and Buyende districts, a lakeshore area with high malaria burden in Uganda. Given its ecological nature, the area provides favorable mosquito breeding sites, which may partly explain the high malaria burden. At the same time, this natural quality emphasizes the need for more stringent measures to combat the high burden. Adherence to IMM guidelines by health workers is one of the vital measures that ought to front this fight.

\section{Level of adherence to malaria diagnosis guidelines}

The proportion of patients/caregivers who reported overall adherence to both appropriate medical history taking (being asked about age, when fever started, symptoms including those of severe illness) and physical examination (having weight and temperature taken) was $8.1 \%$. This finding is much lower than the number reported among children in Bolgatanga Hospital, Ghana which reported high adherence to physical examinations, with 95\% having their body temperature and 94\% having their respiratory and pulse rate taken as recommended in the Ghana national malaria management guidelines [11]. One possible explanation for this stark difference could be due to Uganda's high client load, which may overwhelm providers and deter them from following the 
Table 4 Provider-related factors and adherence to national malaria management guidelines

\begin{tabular}{|c|c|c|c|c|}
\hline \multirow{2}{*}{$\begin{array}{l}\text { Provider demographics }(n=26) \\
\text { Gender }\end{array}$} & \multicolumn{2}{|c|}{ Reported adherence to IMM guidelines } & \multirow[t]{2}{*}{$\begin{array}{l}\text { Chi square test }\left(\mathrm{X}^{2}\right) \text { statistic } \\
\text { (df)/FET }\end{array}$} & \multirow[t]{2}{*}{ p-value } \\
\hline & No & Yes & & \\
\hline Female & $16(88.9)$ & $2(11.1)$ & $0.821(1)$ & 0.563 \\
\hline Male & $6(27.3)$ & $2(50.0)$ & & \\
\hline \multicolumn{5}{|l|}{ Age of providers } \\
\hline 19-24 years & $4(18.2)$ & $0(0.0)$ & & \\
\hline 25-30 years & $12(54.5)$ & $3(75.0)$ & 9.996 & 0.694 \\
\hline $31-36$ years & $3(13.6)$ & $0(0.0)$ & & \\
\hline 37 years and above & $3(13.6)$ & $1(25.0)$ & & \\
\hline \multicolumn{5}{|l|}{ Years worked in current position } \\
\hline $0-5$ & 20 & 3 & & \\
\hline $6-10$ & 2 & 0 & $7.239(5)$ & 0.203 \\
\hline Over 10 & 0 & 1 & & \\
\hline \multicolumn{5}{|c|}{ Training the last 36 months on the national treatment guidelines for malaria?** } \\
\hline No & $16(72.7)$ & $0(0.0)$ & 7.564 & 0.014 \\
\hline Yes & $6(27.3)$ & $4(100)$ & & \\
\hline \multicolumn{5}{|l|}{ Highest level of education attained } \\
\hline Primary education & $7(31.8)$ & $2(50.0)$ & & \\
\hline Secondary education & $6(27.3)$ & $0(0.0)$ & 3.381 & 0.336 \\
\hline Some university & $1(4.5)$ & $1(25.0)$ & & \\
\hline University/college & $8(36.4)$ & $1(25.0)$ & & \\
\hline \multicolumn{5}{|l|}{ Healthcare provider cadre ${ }^{* *}$} \\
\hline Health Assistant/Nursing Assistant/Nursing Aide & $8(36.4)$ & $1(25.0)$ & & \\
\hline Community Medicine Distributor/Nillage Health Team & $1(4.5)$ & $0(0.0)$ & $27.468(7)$ & $<0.001$ \\
\hline Clinical Officer & $1(4.5)$ & $1(25.0)$ & & \\
\hline Nurse/Nursing Officer & $7(31.8)$ & $1(25.0)$ & & \\
\hline Midwife & $3(13.6)$ & $1(25.0)$ & & \\
\hline Laboratory technician/Laboratory assistant & $2(9.1)$ & $0(0.0)$ & & \\
\hline \multicolumn{5}{|c|}{ Provider knowledge about first-line anti-malarials for uncomplicated malaria } \\
\hline Correctly identified first-line medications & $17(77.3)$ & $4(100.0)$ & $1.600(2)$ & 0.449 \\
\hline Incorrectly identified first-line line medications & $4(18.2)$ & $0(0.0)$ & & \\
\hline Admitted did not know & $1(5.5)$ & $0(0.0)$ & & \\
\hline \multicolumn{5}{|l|}{ Provider perceptions towards IMM guidelines } \\
\hline \multicolumn{5}{|c|}{ If a patient comes with mild fever, he/she must be tested before any treatment } \\
\hline Agree & $20(90.9)$ & $4(100.0)$ & $0.688(1)$ & 0.407 \\
\hline Disagree & $2(9.1)$ & $0(0.0)$ & & \\
\hline \multicolumn{5}{|l|}{ Sometimes RDTs do not provide correct results } \\
\hline Agree & $16(72.7)$ & $3(75.0)$ & & \\
\hline Disagree & $5(22.7)$ & $0(0)$ & $2.368(2)$ & 0.306 \\
\hline Neither agree nor disagree & $1(4.6)$ & $1(25.0)$ & & \\
\hline \multicolumn{5}{|l|}{ I do not trust results of RDT } \\
\hline Agree & $17(77.3)$ & $3(75.0)$ & & \\
\hline Disagree & $4(18.2)$ & $1(25.0)$ & $1.143(2)$ & 0.565 \\
\hline Neither agree nor disagree & $1(4.5)$ & $0(0.0)$ & & \\
\hline \multicolumn{5}{|c|}{ There are times when I treat patients with an anti-malarial even when they test negative for malaria as long as they have symptoms for malaria } \\
\hline Agree & $19(86.4)$ & $4(100.0)$ & $0.811(1)$ & 0.368 \\
\hline Disagree & $3(13.6)$ & $0(0.0)$ & & \\
\hline \multicolumn{5}{|l|}{ It is 'okay' to treat a patient with fever without testing } \\
\hline Agree & $7(31.8)$ & $1(25.0)$ & $0.015(1)$ & 0.902 \\
\hline Disagree & $15(68.2)$ & $3(75.0)$ & & \\
\hline
\end{tabular}

Source: primary data

** Statistically significant variable 
Table 5 Facility-related factors and adherence to national malaria management guidelines

\begin{tabular}{|c|c|c|c|c|}
\hline \multirow{2}{*}{$\begin{array}{l}\text { Variable } \\
\text { Level of facility }(n=26)\end{array}$} & \multicolumn{2}{|c|}{$\begin{array}{l}\text { Reported } \\
\text { adherence to IMM } \\
\text { guidelines }\end{array}$} & \multirow[t]{2}{*}{$\begin{array}{l}\text { Chi } \\
\text { square } \\
\text { test (FET) }\end{array}$} & \multirow[t]{2}{*}{ p-value } \\
\hline & No & Yes & & \\
\hline Level II & $11(50.0)$ & $1(25.0)$ & & \\
\hline Level III & $11(50.0)$ & $3(75.0)$ & 0.851 & 0.598 \\
\hline Total & $22(100.0)$ & $4(100.0)$ & & \\
\hline \multicolumn{5}{|l|}{ Facility ownership** } \\
\hline Private & $7(31.8)$ & $1(25.0)$ & & \\
\hline Public & $14(63.6)$ & $0(0.0)$ & 13.517 & 0.001 \\
\hline $\begin{array}{l}\text { Private not-for-profit } \\
\text { (PNFP) }\end{array}$ & $1(4.5)$ & $3(75.0)$ & & \\
\hline Total & $22(100.0)$ & $4(100.0)$ & & \\
\hline
\end{tabular}

Source: primary data

** Statistically significant variable

appropriate steps in diagnosis. Other potential reasons include inadequate medical equipment, such as weighing scales and thermometers.

The $65.5 \%$ of patients in this study who were recommended to do a malaria test is lower than that found in a study in Ghana, in which $76 \%$ of the patients were requested to have laboratory tests done prior to treatment for malaria [11]. This difference could be due to the differences in provider knowledge and perceptions related to malaria diagnosis. For instance, health providers in Uganda believe in clinical diagnosis of malaria rather than testing for the disease [12], so many may not prioritize testing and instead opt to use clinical signs. This preference may be attributed to previous Ministry of Health policies, which condoned diagnosis for malaria based on clinical signs [12]. This observation may also imply that it may take some time for health workers to fully adopt the test-and-treat guidelines, even if current policies shift.

The overall level of malaria diagnosis (laboratory testing and clinical diagnosis) was only $6.1 \%$, which is not in line with the current National Malaria Control Policy in Uganda. This policy recommends microscopy or RDT for confirmation of all suspected malaria cases before prescribing any anti-malarial [3]. It is a deplorable finding, given that poor adherence to the diagnostic guidelines has a direct implication on the treatment given and subsequently the outcome of such treatments [12].

\section{Level of adherence to malaria prescription guidelines}

The finding about adherence to prescription guidelines indicates that close to $65 \%$ of the patients who participated in this study received ACT drug or ACT drug prescription even though only $54 \%$ of those tested were
Table 6 Multivariate analysis of factors associated with adherence to national malaria management guidelines

\begin{tabular}{|c|c|c|c|c|}
\hline \multirow{2}{*}{$\begin{array}{l}\text { Variable } \\
\begin{array}{l}\text { Professional cadres } \\
(n=26)\end{array}\end{array}$} & \multirow[t]{2}{*}{ Odds ratio (OR) } & \multicolumn{2}{|c|}{$95 \% \mathrm{Cl}$ for OR } & \multirow[t]{2}{*}{ p-value } \\
\hline & & Lower & Upper & \\
\hline Clinical officer & 1.000 & & & \\
\hline $\begin{array}{l}\text { Enrolled nurse/nursing } \\
\text { officer }\end{array}$ & 1.891 & 0.030 & 118.772 & 0.763 \\
\hline Midwives & 0.946 & 0.015 & 59.386 & 0.979 \\
\hline $\begin{array}{l}\text { Laboratory technician/ } \\
\text { assistant }\end{array}$ & 1.788 & 0.004 & 885.281 & 0.854 \\
\hline $\begin{array}{l}\text { Health Assistant/Nursing } \\
\text { Assistant/Nursing Aid }\end{array}$ & 1.891 & 0.030 & 118.772 & 0.763 \\
\hline \multicolumn{5}{|c|}{ Received training on IMM guidelines in the past 3 years ${ }^{* *}(n=26)$} \\
\hline Yes & 2.858 & 1.754 & 4.659 & $<0.001$ \\
\hline No & 1.000 & & & \\
\hline \multicolumn{5}{|c|}{ Ownership of the facilities $(n=26)$} \\
\hline Private & 0.006 & 0.002 & 0.094 & 0.086 \\
\hline Government & 0.026 & 0.003 & 0.193 & 0.251 \\
\hline Private not for profit & 1.000 & & & \\
\hline
\end{tabular}

Source: primary data

** Statistically significant variable

positive. This is not surprising, given that in the provider interviews, most providers agreed that they would go ahead and treat a patient with anti-malaria drug even when the test results were negative. This finding is consistent with the earlier findings of a similar study among public health workers in the Kamuli district, which found that health providers prescribed anti-malarial drugs for almost all patients who presented having fever without doing confirmatory laboratory tests [13]. This action contradicts the national malaria management guidelines that require testing of all suspected cases of malaria prior to treatment with anti-malarial drugs [3]. Furthermore, this finding also reflects provider practices in relation to malaria management across sub-Saharan Africa. Another study in Ghana found 98\% non-adherence to the national prescription guidelines with regard to prescription of first-line anti-malarial drugs for management of severe malaria [11].

Of major concern, $40 \%$ of patients with negative malaria test results in this study received ACT drug or other anti-malarial drug prescription. This result implies that health workers follow the clinical diagnosis guidelines and use fever as the major symptom of malaria [11]. A similar finding was reported in a retrospective audit of patient records in two public hospitals in Nigeria and showed that $58 \%$ of patients who tested negative received anti-malarial drugs [14]. These findings portray similarity in health provider practices between African 
countries. Study findings were also consistent with studies in other developing countries by indicating that inappropriate prescription and use of ineffective anti-malarial drugs persists in both public and private health facilities [15] and substantial inappropriate treatment practices, including treating people with negative malaria test results [16]. Policy makers ought to focus on dispelling the belief that fever is an indicator of malaria infection. This can be done through refresher training on the new policy guidelines. Similarly, $19 \%$ of patients with a positive test result for malaria were not given ACT drug or any other prescription for anti-malaria drugs, which also defies the current treatment guidelines for malaria that require recommending an ACT for every uncomplicated malaria case. The study was not able to establish why patients with positive results were not prescribed or given an ACT.

The observed $3.1 \%$ overall level of adherence to IMM guidelines is extremely low, especially for lakeshore areas such as Buyende and Kaliro. This finding may translate into a larger public health concern since non-adherence can lead to drug resistance, resource waste, adverse health outcomes including death, and lower healthcare quality by health facilities [17]. The low level of adherence may be due to negative provider perceptions; an astonishing $88 \%$ of health workers interviewed in this study agreed that they treat patients with anti-malarial even though they have negative test results.

\section{Factors influencing adherence to the IMM guidelines}

Training on how to use national malaria treatment guidelines, the professional cadre of the healthcare providers, and facility ownership were the only factors that were significantly associated with adherence to malaria management guidelines. At the same time, IMM training in the past 3 years was the only factor that independently influenced adherence. This result implies that training healthcare providers on national malaria management guidelines should improve their levels of adherence to the guidelines. However, a study among public health facilities in the Kamuli district in Eastern Uganda contradicts this finding. It found no statistically significant association between attending malaria-specific continuing medical education (CME) sessions and increased adherence to the national malaria treatment guidelines [13]. This contradiction may be due to the difference in the definition of training between this study and the study in Kamuli. Another explanation could be because the Kamuli study was solely among public health facilities where training may be routine and identical for all health workers, whereas the present study was also conducted in private health facilities where training on IMM may not be routine.

\section{Study limitations}

One limitation is that adherence to IMM guidelines was patient-reported rather than observed. This aspect could have caused bias in the information provided by patients. However, the researchers believe that there were few instances of bias since patient respondents would lack any negative motives towards health workers or may not be sure of what healthcare workers should or should not be doing. It is believed that being patient-reported did not affect the results.

Another limitation is that the number of health workers was very low, which could have impacted the measurement of the factors that may influence adherence to the IMM guidelines. Interviewing more health workers would have required covering more area, since the number of health workers in Uganda in generally low, and consequently more funding and resources. On the other hand, the number considered in this study may be representative of the healthcare workers in the lakeshore areas of Kaliro and Buyende districts.

In addition, the cross-sectional nature of this study poses a limitation in that inference between IMM adherence and associated factors is difficult to make. A longitudinal study should be considered in future to make further conclusions on this subject.

\section{Conclusions}

The overall level of adherence to the national malaria management guidelines in Kaliro and Buyende districts was very low, with only $3.1 \%$ of the patients reported being treated in line with national IMM guidelines. Training in the last 3 years was the only factor that independently influenced adherence to the national malaria management guidelines among the providers. Policy makers ought to focus on dispelling the belief that fever is an indicator of malaria infection. This can be done through refresher training on new policy guidelines.

\section{Authors' contributions}

HK designed the study, organized the research assistants, and drafted the initial draft of this manuscript. SK provided guidance on the study design and provided revisions of the manuscript. LN finalized the data analysis, conducted final revisions of the draft, and organized the manuscript for publication. All authors read and approved the final manuscript.

\section{Author details \\ ${ }^{1}$ International Health Sciences University, Kampala, Uganda. ${ }^{2}$ PACE Uganda, PSI, Kampala, Uganda.}

\section{Acknowledgements}

The authors would like to acknowledge the Institute of Public Health and Management of the International Health Sciences University, PACE Uganda, PSI Uganda, all persons who facilitated and coordinated the data collection process, and every study participant. 


\section{Competing interests}

The authors declare that they have no competing interests.

\section{Availability of data and materials}

Availability of data can be requested by contacting kaula.henry@gmail.com or nunezluigi@icloud.com.

\section{Consent for publication}

Not applicable.

\section{Ethical approval and consent to participate}

Approval was granted by the ethical review board of the International Health Sciences University in Uganda. Oral consent was provided from those in charge of each health facility where data was collected. Furthermore, oral consent was obtained from every respondent before being interviewed and personal identifiers were avoided.

\section{Funding}

The research was funded by the researchers and authors of the manuscript.

\section{Publisher's Note}

Springer Nature remains neutral with regard to jurisdictional claims in published maps and institutional affiliations.

\section{Received: 14 June 2018 Accepted: 9 November 2018}

Published online: 19 November 2018

\section{References}

1. WHO. World malaria report 2014. Geneva: World Health Organization; 2014.

2. WHO. Test. Treat. Track. Scaling up diagnostic testing, treatment and surveillance for malaria. Geneva: World Health Organization; 2012.

3. Uganda Ministry Of Health. Uganda clinical guidelines 2012. Kampala, 2012. http://health.go.ug/docs/UCG_2012.pdf. Accessed 29 May 2018.

4. Malaria Consortium. Malaria in Uganda. 2016. https://www.malariacon sortium.org/pages/80.htm. Accessed 29 May 2018.

5. National Malaria Control Programme, Abt Associates and the INFORM Project (2013). An epidemiological profile of malaria and its control in Uganda. A report prepared for the Ministry of Health, the Roll Back Malaria Partnership and the Department for International Development UK. October, 2013.
6. Uganda Bureau of Statistics. Statistical abstract. 2014. http://www.ubos. org/onlinefiles/uploads/ubos/statistical_abstracts/Statistical_Abstr act_2014.pdf. Accessed 29 May 2018.

7. Uganda Bureau of Statistics. The National Population and Housing Census 2014-main report, Kampala, Uganda. 2016. Accessed 02 May 2017.

8. Kish L. Survey sampling. New York: John Wiley \& Sons, Inc.; 1965.

9. Uganda Bureau of Statistics and ICF International. Uganda Malaria Indicator Survey 2014-15: Key Indicators. Kampala, Uganda, and Rockville, Maryland, USA: UBOS and ICF International. Accessed 02 May 2017.

10. Uganda Hospital and Health Centre. Census Survey, 2014. Accessed 12 Sept 2018. http://who.int/healthinfo/systems/Sara_H_Uga_Results_2014. pdf.

11. Zoyah JC, Diedong AL. Health professionals' compliance with national treatment guidelines for treatment of severe malaria in children in Bolgatanga Hospital, Upper East, Ghana. Int J Humanities Soc Sci. 2014;4:119-33.

12. Uganda Ministry of Health. The Uganda malaria reduction strategic plan 2014-2020. Malaria Control Programme, 2015.

13. Bawate C, Callender Carter ST, Nsajju B, Bwayo D. Factors affecting adherence to national malaria treatment quidelines in management of malaria among public healthcare workers in Kamuli District, Uganda. Malar J. 2016;15:112.

14. Ezenduka CC, Ogbonna BO, Ekwunife OI, Onkota MJ, Esimone CO. Drug use pattern for uncomplicated malaria in medicine retail outlets in Enugu Urban, southeast Nigeria: implications for malaria treatment policy. Malar J. 2014;13:243.

15. Hensen B, Paintain LS, Shretta R, Bruce J, Jones C, Webster J. Taking stock, provider prescribing practices in the presence and absence of ACT stock. Malar J. 2010;10:218.

16. Mangham LJ, Cundill B, Ezeoke O, Nwala E, Uzochukwu C, Wiseman V, et al. Treatment of uncomplicated malaria at public health facilities and medicine retailers in south-eastern Nigeria. Malar J. 2011;10:155.

17. De Bruycker M, Den Bergh RV, Dahmane A, Khogali M, Schiavetti B, Nzomukunda Y, et al. Non-adherence to standard treatment guidelines in a rural paediatrics hospital in Sierra Leone. Public Health Action. 2013;3:121.
Ready to submit your research? Choose BMC and benefit from:

- fast, convenient online submission

- thorough peer review by experienced researchers in your field

- rapid publication on acceptance

- support for research data, including large and complex data types

- gold Open Access which fosters wider collaboration and increased citations

- maximum visibility for your research: over $100 \mathrm{M}$ website views per year

At BMC, research is always in progress.

Learn more biomedcentral.com/submissions 